\title{
Meeting report: Research topics in gastrointestinal disease $\mathrm{VI}$
}

\author{
Organizing Committee: \\ Gordon R Greenberg MD, University of Toronto, Toronto, Ontario \\ Ken Croitoru MD FRCP, McMaster University, Hamilton, Ontario \\ Kris Chadee PhD, Chair, CAG Research Committee; University of Calgary, Calgary, Alberta \\ Paul Sinclair MSc, Executive Director, CAG
}

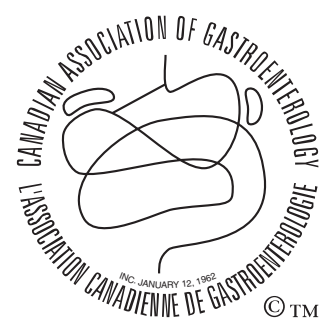

En français voir page 127
$\mathrm{R}$ ecent advances in gastrointestinal (GI) diseases are a direct result of the rapid development in fundamental research using cellular and molecular biology approaches. These approaches have helped define normal physiological processes of the GI tract and the pathogenesis of disease mechanisms. The Canadian GI research communities are world leaders in contributing to these efforts in all disciplines relevant to GI disease. This success has been achieved by fostering an excellent cohort of graduate and postgraduate research trainees involved in GI research at institutions across Canada. Many of these trainees are funded by the Canadian Association of Gastroenterology (CAG) in collaboration with the Canadian Institutes of Health Research (CIHR), a number of industry partners and the Crohn's and Colitis Foundation of Canada.

In recognition of the value of the Canadian GI trainees outstanding research contributions, and to promote and encourage the continued efforts of the graduate and postgraduate research trainees in basic and clinical sciences, the CAG, in conjunction with AstraZeneca Canada Inc and the CIHR, held the sixth Symposium on Research Topics in Gastrointestinal Disease, October 13 to 15, 2006 (Figure 1). The goal of this meeting was to provide research trainees with an opportunity to informally present their original research, from diverse disciplines, to their peers and to a selection of faculty from across Canada. In this forum, trainees actively participated in the discussions of papers in an open setting. This year's program consisted of a series of superb presentations describing cutting-edge research with 38 podium scientific presentations of basic and clinical GI-related research, covering mechanisms of gut inflammation, enteric flora and epithelial barrier functions, hormones that modulate gut responses, epithelial and transport mechanisms, pathogens that initiate inflammatory processes and cancer, and gastric ulceration and healing mechanisms. This year's keynote lecture was given by Dr John Wallace on "Hydrogen sulphide and inflammation: What's all the stink about?" The emphasis was on the emerging anti-inflammatory role of hydrogen peroxide and how this important information can have potential commercial benefits in the development of therapeutics in inflammatory disorders.

Like previous years, a major success of the meeting was that it also provided a venue in which trainees could meet their peers from across Canada and initiate collaborative opportunities, thus developing contacts for their future research career and the future of Canadian GI research. This aspect was commented on by trainees attending for the second time and in the overall feedback responses that were received during the meeting. All participants evaluated the meeting as excellent and described the experience as rewarding and a superb learning forum. Thus, as a result of this enormously successful symposium, the organizing committee, the CAG and AstraZeneca Canada Inc are committed to holding this meeting on a regular basis. Plans are already underway for a fall 2007 meeting, in which, once again, research abstract submissions relating to all facets of GI health and disease will be welcomed. Canadian investigators with basic and clinical GI research programs are strongly requested to lend support to this important endeavor by encouraging the participation of their trainees and graduate students.

ACKNOWLEDGEMENTS: The organizers would particularly like to thank AstraZeneca Canada and the CIHR for their generous support of this meeting, the sixth of its kind in a series that will continue to advance gastroenterology in Canada. In addition, we wish to thank the invited faculty, Drs William Paterson, Nicola Jones and John Wallace for their commitment and valuable contributions to this meeting.

The CAG is proud to acknowledge its Benefactor Corporate Sponsors:

\begin{tabular}{|c|c|c|c|}
\hline Abbott Laboratories Ltd & Nycomed (formerly ALTANA Pharma & AstraZeneca Canada Inc & Axcan Pharma Inc \\
\hline Janssen-Ortho Inc & Olympus Canada Inc & Procter \& Gamble Pharmaceuticals & Schering Canada Inc \\
\hline
\end{tabular}




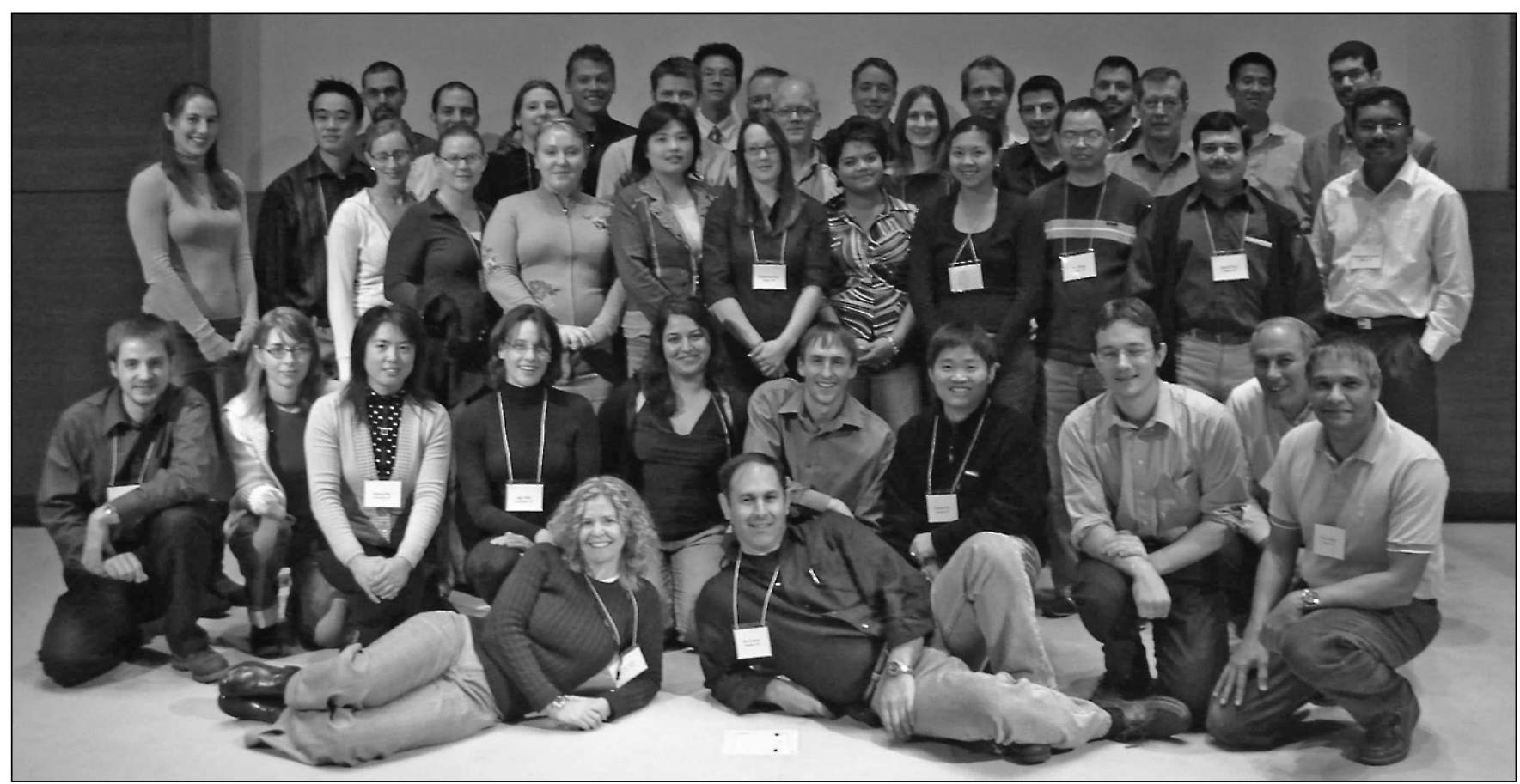

Figure 1) Participants and faculty in the sixth Symposium on Research Topics in Gastrointestinal Disease, October 13 to 15, 2006 / Les participants et les professeurs au sixième symposium sur des sujets de recherche en maladies gastro-intestinales, du 13 au 15 octobre 2006. Participants: Eric Albert, Halifax, Nova Scotia; Jody Backer, Edmonton, Alberta; Jackie Caldwell, Hamilton, Ontario; Philippe Cammisotto, Montreal, Quebec; Chuanbin Dai, Vancouver, British Columbia; Indranil Dey, Calgary, Alberta; Charlotte D’Mello, Calgary, Alberta; Philip Dubé, Toronto, Ontario; Genevieve Dudar, Calgary, Alberta; Rami El-Sharkawy, Hamilton, Ontario; Mélanie Gareau, Hamilton, Ontario; Christina Hirota, Hamilton, Ontario; Nathan Ho, London, Ontario; Ian Hons, Calgary, Alberta; Patrick Hui, Kingston, Ontario; Niall Hyland, Calgary, Alberta; Catherine Ivory, Calgary, Alberta; Matt Klompus, Edmonton, Alberta; Dirk Lange, London, Ontario; Manigandan Lejeune, Calgary, Alberta; Gareth Lim, Toronto, Ontario; Travis Murdoch, Edmonton, Alberta; Brent Parkins, Calgary, Alberta; Colin Reardon, Calgary, Alberta; Reem Rostom, Halifax, Nova Scotia; Joanna Rybicka, Calgary, Alberta; Grace Shen-Tu, Toronto, Ontario; Jesse Siffledeen, Edmonton, Alberta; Roger Stanzel, Kingston, Ontario; Michelle Tang, Vancouver, British Columbia; Inga Teller, Sherbrooke, Quebec; Thomas Walters, Toronto, Ontario; Elizabeth White, Hamilton, Ontario; Eytan Wine, Toronto, Ontario; Xiujuan Wu, Vancouver, British Columbia; Rui Zhang, Calgary, Alberta. Faculty / Professeurs : Dr Kris Chadee, Calgary, Alberta; Dr Nicola Jones, Toronto, Ontario; Dr Gordon R Greenberg, Toronto, Ontario; Dr William Paterson, Kingston, Ontario; Dr Ken Croitoru, Hamilton, Ontario; Dr John Wallace, Calgary, Alberta 


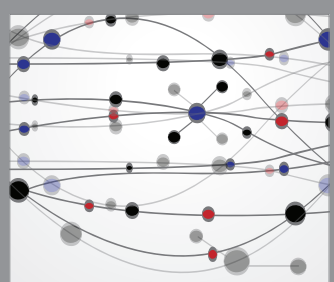

The Scientific World Journal
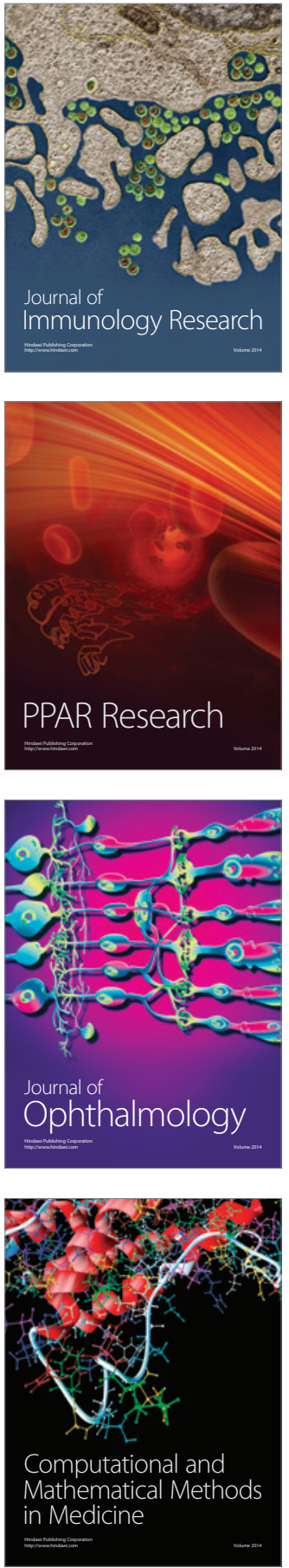

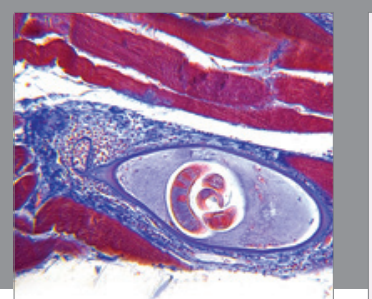

Gastroenterology Research and Practice

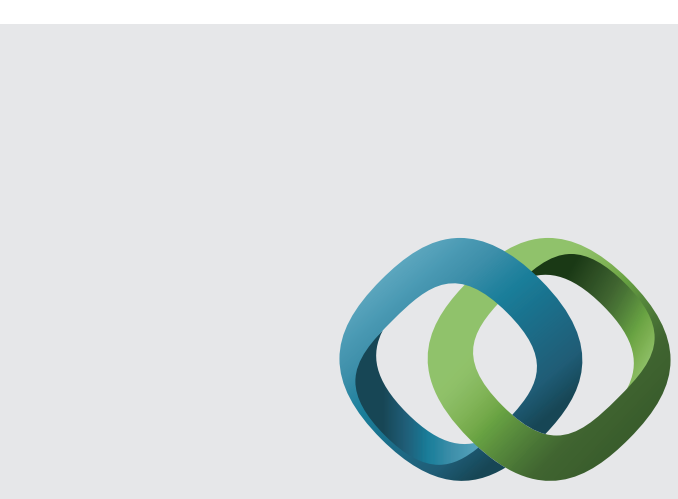

\section{Hindawi}

Submit your manuscripts at

http://www.hindawi.com
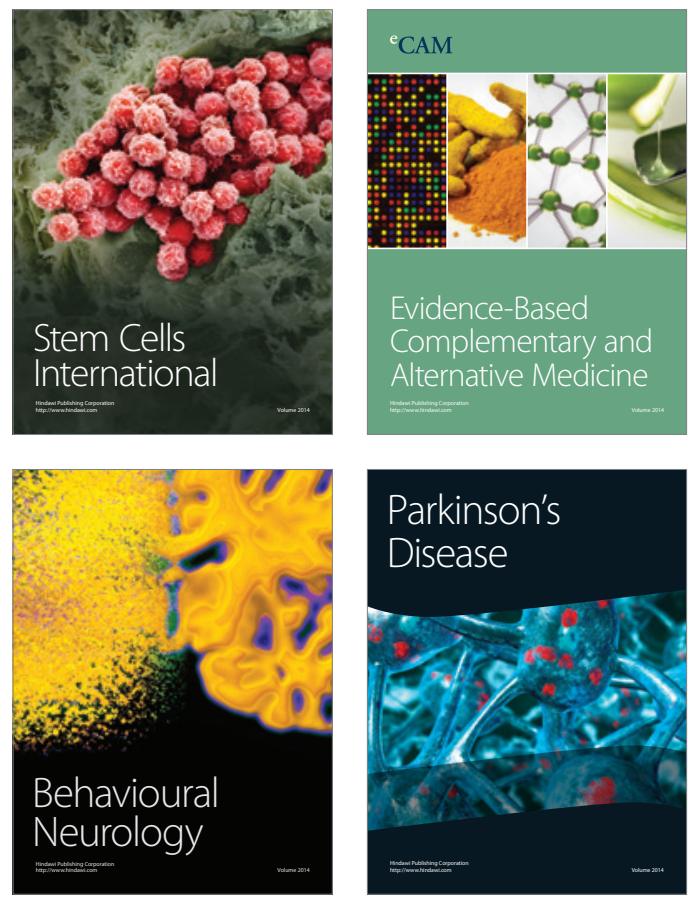
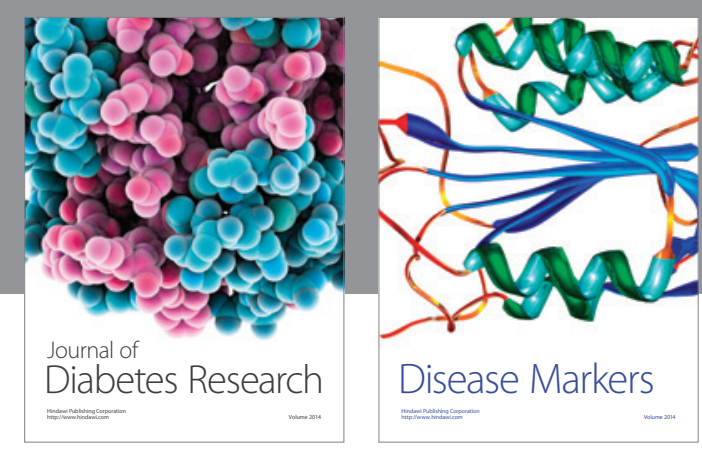

Disease Markers
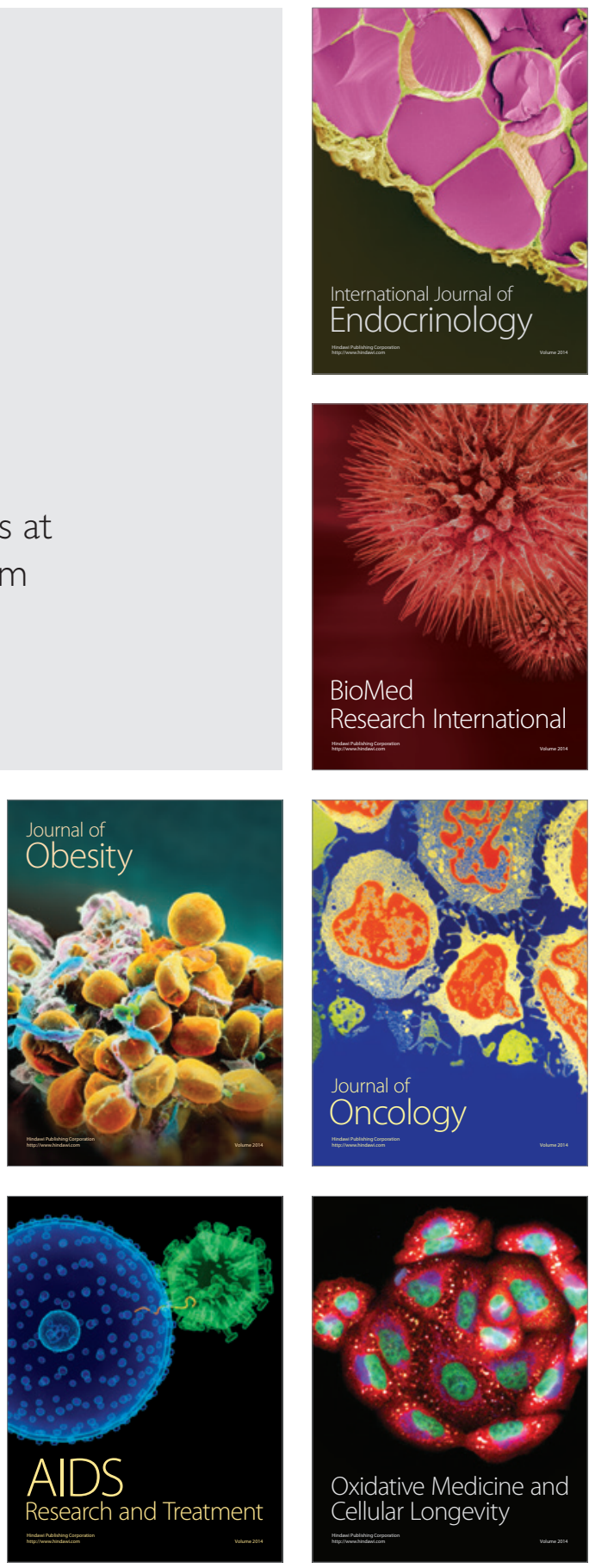